\section{IBM last come, first served again}

Washington

IBM. AFTER two years of waiting and watching the office computer market. finally introduced its local area network system last week. The form of topology of the network. by which personal computers and other peripheral devices can interactively communicate, was announced in May 1984, when the company put on sale the coaxial cable that would link the devices in the network, but told customers they would have to wait two to three years for the rest of the system. Although many find IBM's new network disappointing compared with what other commercially available systems can do, the official entry of IBM into the office network market will remove much uncertainty from a notoriously slow-moving part of the computer marketplace.

The system announced last week consists of the software to link the devices and a set of chips designed by Texas Instruments that will permit the computers to be attached to the network. The Texas highspeed interface allows operations at $4 \mathrm{mil}$ lion bits per second. IBM has effectively introduced two networks, available in the first quarter of 1986, one that can link up to 72 computers on existing telephone cables and another that can connect 260 computers but requires the expensive coaxial cable.

The main complaint about the system is that IBM has not developed the technology to allow personal computers to interact intelligently with larger computers on the network. Personal computers can have access to information from mainframes, but frustrated customers must again wait until IBM introduces the interface to allow the two to interact. The company refuses to predict a date for this step.

Local area networks are not new - the most common, Ethernet, was introduced six years ago and can do much that IBM's cannot. Most existing networks use either bus or star topologies. A bus network connects peripherals to a single central cable, allowing further devices to be added easily; if one device breaks down, the system can keep on operating. The disadvantage of this system is that each component must be checked when a fault occurs; technically, the network is best suited to short distances.

A star network links peripherals through a central computer, which makes it easy to maintain but means that a breakdown of the central computer stops the whole network.

IBM has chosen to sell a network in which a series of peripherals is connected in a ring around which an electronic signal, or token, constantly circulates. A message can be attached to the token and sent to another unit in the network, which then uses the token to acknowledge the message. No other data can be transmitted during this time. One problem with such token-ring systems is that the loss of one peripheral can close down the network; the system is also difficult to service and expand.

One complaint of Digital, IBM's competitor that offers the Ethernet system, is that established networks are standardized whereas IBM's is not. But seven major computer companies rushed to announce accommodations to their products to make them compatible with IBM's network within a day of IBM's
Information technology

\section{Brussels}

Esprit, the European Commission's proud programme of collaborative research in information technology, has emerged slightly tarnished from a review of its first eighteen months of operation. The mid-term review has been carried out by a panel of independent experts whose chairman is Dr Pannenborg, chairman of the Netherlands Centre of Technology Trends and previously a vice-chairman of Philips NV.

The panel acknowledges that Esprit has helped to bring European companies and institutions together on precompetitive research, but says that the European Commission's administration of the programme has been seriously deficient. It recommends that for the remaining phases of the programme the Commission should concentrate resources on a smaller number of larger projects.

The Pannenborg review applauds the role of Esprit as a catalyst in a field in which only a quarter of Europe's needs can be met indigenously. The review also says that Esprit, as the first transnational project on such a scale in such a field, appears to be an effective mechanism for research collaboration. Saying that there has not yet been time enough to judge the success of individual projects, the review goes on to guess that Esprit by itself will not ensure an effective information technology industry in Europe, and that governments will have to pay some attention to the subsequent need for demonstration projects, prototype development and even production engineering.

The review has been based on the experience of 131 European companies working on Esprit projects, most of which seem to have found their collaborative work valuable. For the smaller companies, the 20 per cent or so increase of overhead costs entailed was considered well worth the opportunity for joint working. The development of European standards was singled out for especial praise announcement. Such is IBM's domination of the computer market that any product it introduces becomes a de facto standard.

For how much longer will IBM be able to sit back and wait for others to test its markets before introducing new products? Its token-ring system may well remove some of the uncertainties and customers" nervousness from the office computer market, opening it up for customers and rival companies alike. But the long-awaited 3090 quad processor system. IBM's answer to supercomputers such as those produced by Cray and Cyber, could be a different story - customers for supercomputers are few and far between and IBM could find it has missed that particular boat.

Maxine Clarke

\title{
Poor half-term report for Esprit
}

by many of the companies.

Most of the criticisms in the review are directed at the European Commission for having fallen down on evaluation and on the provision of communications between participants. Failures of communication hit the smallest companies and research institutes hardest, while delays in returning contracts are said to have caused cashflow problems among the smaller companies. The review complains that the Commission's staff responsible for administering Esprit lacked industrial experience. Those responsible for evaluating applications for Esprit funds have been variously described, by participating companies, as "too academic", "lacking in knowledge" and "not always impartial".

Another common complaint is that the Esprit projects taken together do not take account of the strategic needs of a successful European industry.

The review panel recommends that the future phases of the Esprit programme should be organized in the three broad areas of hardware, software and applications and that more attention should be paid to the strategic and commercial importance of new projects.

For the second phase of the Esprit programme, the review panel wants to see a bigger budget, able to support demonstration projects as well as research. It suggests a two-tier system for the evaluation of project proposals and a more widely representative advisory board to supervise the programme. It would like to see a European network of centres of excellence as well as research fellowships.

What will happen to the panel's recommendations is far from clear. After only eighteen months, the first phase of Esprit has already eaten through most of the European Communities' contribution of 750 million ECU, originally meant to last for five years. The future will depend largely on whether the member governments are willing to find more money.

Anna Lubinska 